\title{
La Ruta de la Integración Latinoamericana (RILA), su influencia cultural y desafíos turísticos
}

\author{
A Rota de Integração Latino-Americana (RILA), sua influência cultural e \\ desafios turísticos \\ The Latin American Integration Route (RILA), its cultural influence and \\ tourism challenges
}

\author{
Magali Luzio Ferreira ${ }^{1}$ \\ Maria Augusta de Castilho ${ }^{1}$ \\ Waldir Leonel ${ }^{1}$
}

Recibido el 28 de jun. de 2021; revisado e aprobado el 28 sept. de 2021; aceptado el 13 de oct. de 2021 DOI: http://dx.doi.org/10.20435/inter.v22i4.3446

\begin{abstract}
Resumen: Esta investigación tiene como objetivo sacar a la luz la reflexión histórica sobre la creación e importancia de las formas interaccionistas a lo largo del proceso histórico del mundo, desde las primeras civilizaciones hasta la contemporaneidad. Para realizar el estudio reflexivo y comprender la necesidad de esta unión territorial, se utilizó el método deductivo con cobertura sistémica, a través de bibliotecas, libros, periódicos, sitios web, señalando los trabajos que daban soporte al trabajo en pantalla. El estudio incluye autores que trabajan sobre el contexto histórico como: Pinsky (2005) y Fausto (2013); concepto de espacio enfatizado por Raffestin (2013); lo diferente y lo nuevo, destacado por Canclini (2003) y también hay aspectos del turismo que presenta Barreto (2016). Sedentario, con la necesidad política de una demarcación fronteriza como las grandes murallas que dividen enemistades, ya sea por razones ideológicas o económicas. Sin embargo, las innovaciones del estrechamiento territorial que actualmente dependen de las rutas turísticas, que buscan no solo la facilitación económica, sino también el entretenimiento vinculado a las interacciones culturales. La "Ruta de la Integración Latinoamericana" (RILA) El proyecto crea relaciones de medidas económicas necesarias y visibilidad cultural que promueve la expansión del mercado turístico, con propuestas innovadoras para el turismo local y se puede transformar en un corredor para el flujo de la producción agrícola de Brasil, Paraguay, Chile y Argentina y privilegiar la cultura local a través de diversos segmentos de ocio
\end{abstract}

Palabras clave: interacciones territoriales; iconos culturales; demanda turística.

Resumo: Esta pesquisa tem como objetivo trazer à tona a reflexão histórica sobre a criação e a importância de vias interacionistas ao longo do processo histórico de mundo, desde as primeiras civilizações a contemporaneidade. Para a realização do estudo reflexivo e de entendimento da necessidade desta união territorial, utilizou-se o método dedutivo com abrangência sistêmica, por meio de bibliotecas, livros, jornais, sites, assinalando as obras que forneceram esteios ao trabalho em tela. O estudo contempla autores que trabalham o contexto histórico como: Pinsky (2005) e Fausto (2013); conceito de espaço enfatizado por Raffestin (2013); o diferente e o novo, destacado por Canclini (2003) e há também os aspectos do turismo apresentado por Barreto (2016). Identificam-se vias de mobilidade humana em busca de sobrevivência do homem nômade ao sedentário, com a necessidade política da demarcação limítrofe como as grandes muralhas dividindo feudos, quer seja por questões de divergências ideológicas ou econômicas. Contudo, as inovações de estreitamento territorial contam atualmente com as rotas turísticas, que buscam não só a facilitação econômica, bem como o entretenimento conectado às interações culturais. O projeto "Rota de Integração Latino-Americana" (RILA) cria relações de providências econômicas necessárias e visibilidade cultural que promove a expansão do mercado turístico, com propostas inovadoras para o turismo local e pode se transformar em um corredor de escoamento da produção agrícola de Brasil, Paraguai, Chile e Argentina. Os resultados apontam evidências que privilegiam a cultura local por meio de diversos segmentos de lazer. Palavras-chave: interações territoriais; ícones culturais; demanda turística.

Abstract: This research aims to bring to light the historical reflection on the creation and importance of interactionist ways throughout the historical process of the world, from the first civilizations to contemporaneity. To carry out the reflective study and to understand the need for this territorial union, the deductive method was used with systemic coverage, through libraries, books, newspapers, websites, pointing out the works that provided support to the work on screen. The study includes authors who work on the historical context such as:

\footnotetext{
${ }^{1}$ Universidade Católica Dom Bosco (UCDB), Campo Grande, Mato Grosso do Sul, Brasil.
} 
Pinsky (2005) and Fausto (2013); concept of space emphasized by Raffestin (2013); the different and the new, highlighted by Canclini (2003) and there are also aspects of tourism presented by Barreto (2016). sedentary, with the political need for borderline demarcation such as the great walls dividing feuds, whether for reasons of ideological or economic differences. However, the territorial narrowing innovations that currently rely on tourist routes, which seek not only economic facilitation, as well as entertainment connected to cultural interactions. The "Latin American Integration Route" (RILA) project creates relationships of necessary economic measures and cultural visibility that promotes the expansion of the tourist market, with innovative proposals for local tourism and can be transformed into a corridor for the flow of agricultural production from Brazil, Paraguay, Chile and Argentina. and privilege local culture through various leisure segments.

Keywords: territorial interactions; cultural icons; tourist demand.

\section{INTRODUCCIÓN}

La necesidad humana de interacciones es parte de su esencia. Como siempre hemos escuchado que el ser humano no vive aislado, este aborda el tema intrínsecamente, cuando se mencionan las primeras interacciones humanas, el período paleolítico con el nomadismo y el neolítico con el sedentarismo. Las interacciones prehistóricas llaman la atención sobre los estudios arqueológicos, los primeros canales de riego y las discusiones sobre el espacio, el territorio y la territorialidad que se extienden en la Edad Media, en los hitos históricos del colonialismo al imperialismo, con la apertura de caminos correlacionados con la economía mundial contemporánea. Establece a las presentaciones de canales con infraestructura moderna, haciendo mención histórica de las primeras formas de explotación y ocupación territorial brasileña, hacia centro-oeste, así como interpretando el poder cultural local para la Ruta de Interconexión Latinoamericana (RILA) con propuestas innovadoras para el turismo local.

\section{ASPECTOS GENERALES DEL MARCO TEÓRICO}

\subsection{Necesidades de interacción humana}

Siempre hemos sabido que los seres humanos estamos dotados de una capacidad intrínseca de comunicación. Esto no solo se debe a las observaciones conductuales a lo largo de la evolución humana, sino también a los registros bibliográficos, como el de Fernandes (2016, p. 8), afirmando que: "La práctica de la comunicación humana se convierte en la propia historia de toda su existencia". Existe, por lo tanto, una concomitancia histórica entre la historia del hombre y las comunicaciones, verbales y no verbales, y esto incluye los caminos que fortalecen las relaciones. Rocha (1997, p. 154 apud PERLES, 2007, p. 2), destaca la comunicación como: "1. acto de comunicar; información, aviso; 2. pasaje, camino, enlace". En este análisis, los períodos históricos y su economía muestran una imagen creciente de las formas de interacciones humanas.

\subsection{Interacciones humanas prehistóricas}

El período de la aparición de los primeros caminos de movilidad humana en busca de supervivencia, el hambre, la necesidad de refugio, hizo que el hombre se lanzara a tierras inexploradas. Prous (2006, p. 14), "Llama la atención no menos importante sobre los estudios arqueológicos paleo ambientes: clima, vegetación, fauna y topografía, que cambian con el tiempo, influyendo en las colectividades humanas". En consecuencia, esos fenómenos caracterizan los hábitos, la vida cotidiana de un grupo determinado (Mapa 1). 
Mapa 1 - Los mejores sitios arqueológicos del mundo

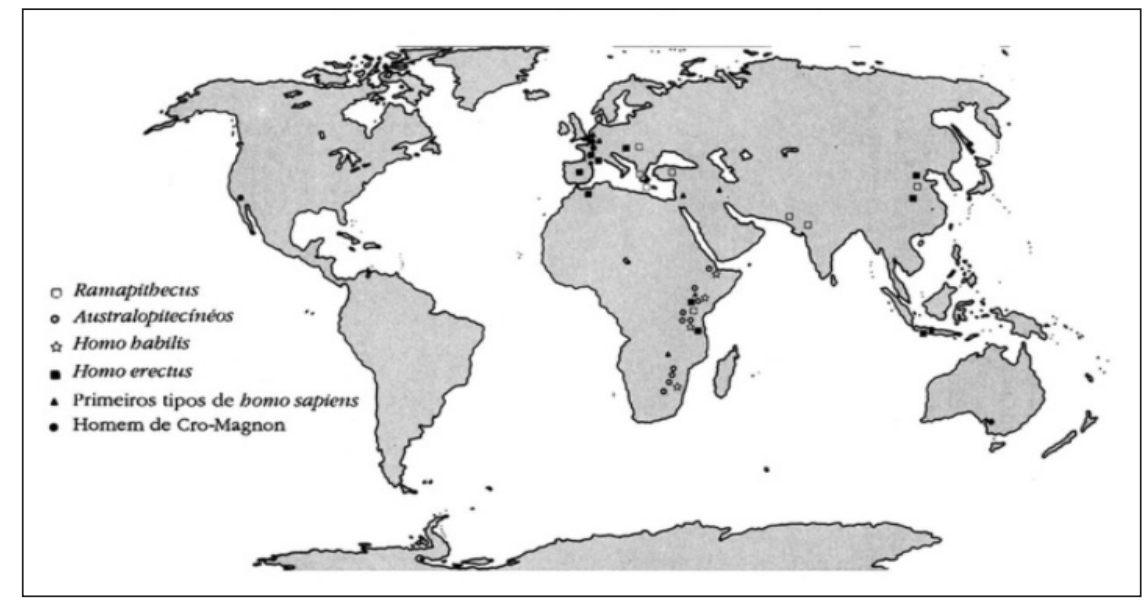

Fuente: Pinsky (2005).

Pinsky (2005), señala que estos sitios arqueológicos explorados por especialistas son pistas, para que uno pueda entender el origen humano y su evolución en el mundo. Es cierto que muchos de estos fósiles son indicadores de lo que es la humanidad hoy día. Aún así, muchos de estos estudios todavía se presentan como hipótesis. Sin embargo, es necesario abordar en cuestión, aunque sea superficialmente, porque facilitan la comprensión y el desencadenamiento del curso histórico humano (Mapa 2).

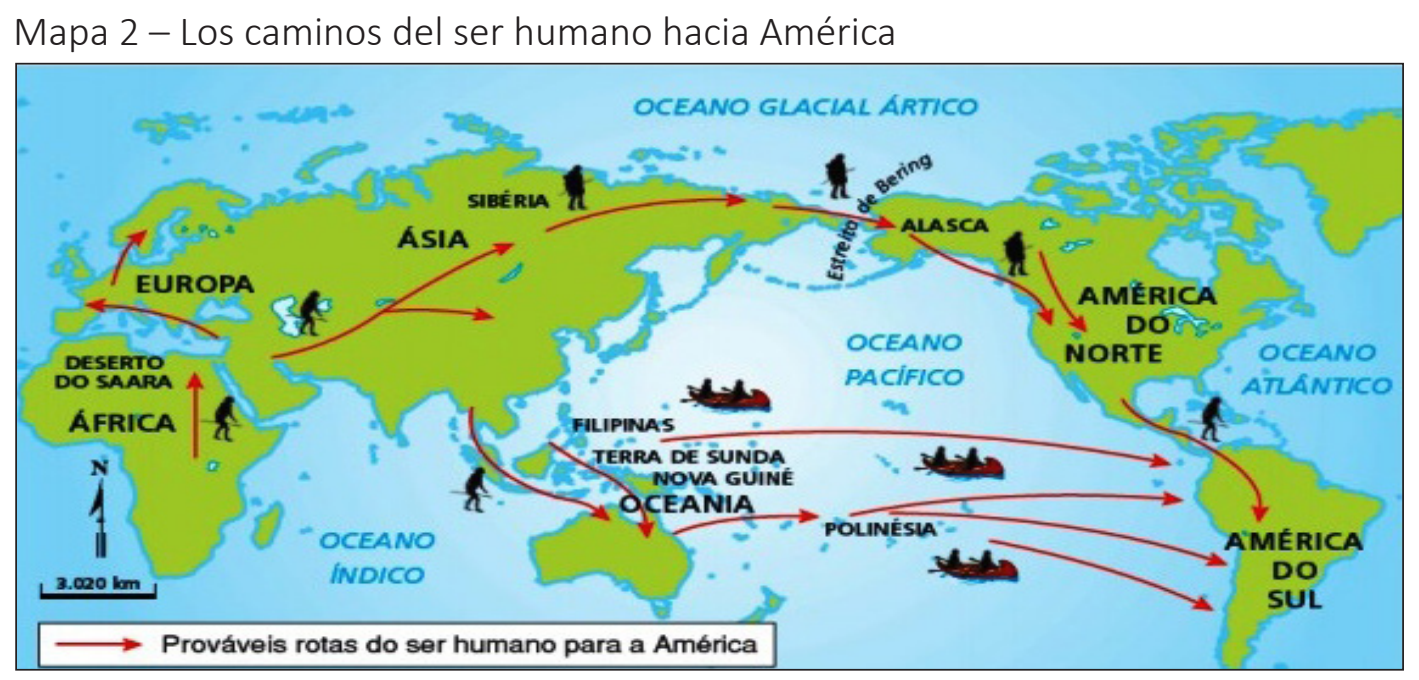

Fuente: Naquet-Vidal e Bertin (1987).

En busca de subsistencias se dieron los primeros pasos exploratorios, y así, en este inicio abriendo caminos para la circulación y la comunicación, ya que son posibles, algunos desarrollos para el nacimiento de las ciudades (período neolítico) inaugurando la propia vida sedentaria. A diferencia de la fase pasada, en esta, el hombre deja de ser parcialmente nómada, debido a que su circulación continúa a lo largo de su historia haciendo interacciones para su estabilidad económica.

Desde el origen humano hasta los caminos penetrantes, para la construcción a la que 
se puede mirar a nuestro alrededor, se dice que los trabajos fueron superados por nuestros antepasados para convertirse en lo que somos. El principal hito histórico es que todo comienza con una fijación espacial y así conseguir lo necesario para su comunidad.

\subsection{Interacciones sedentarias}

El hombre de nómada se vuelve sedentario, viviendo a las orillas de los rios, formando comunidades, y así se originaron las ciudades. Desde el río Nilo en Egipto, del rio Éufrates hasta los pueblos de la antigua Mesopotamia (hoy Irán e Irak), surgieron numerosas civilizaciones, facilitando su desarrollo que se extendió, en un principio, debido a los canales de riego (Gráfico 1).

Cuadro 1 - Evolución Urbana en la antigüedad

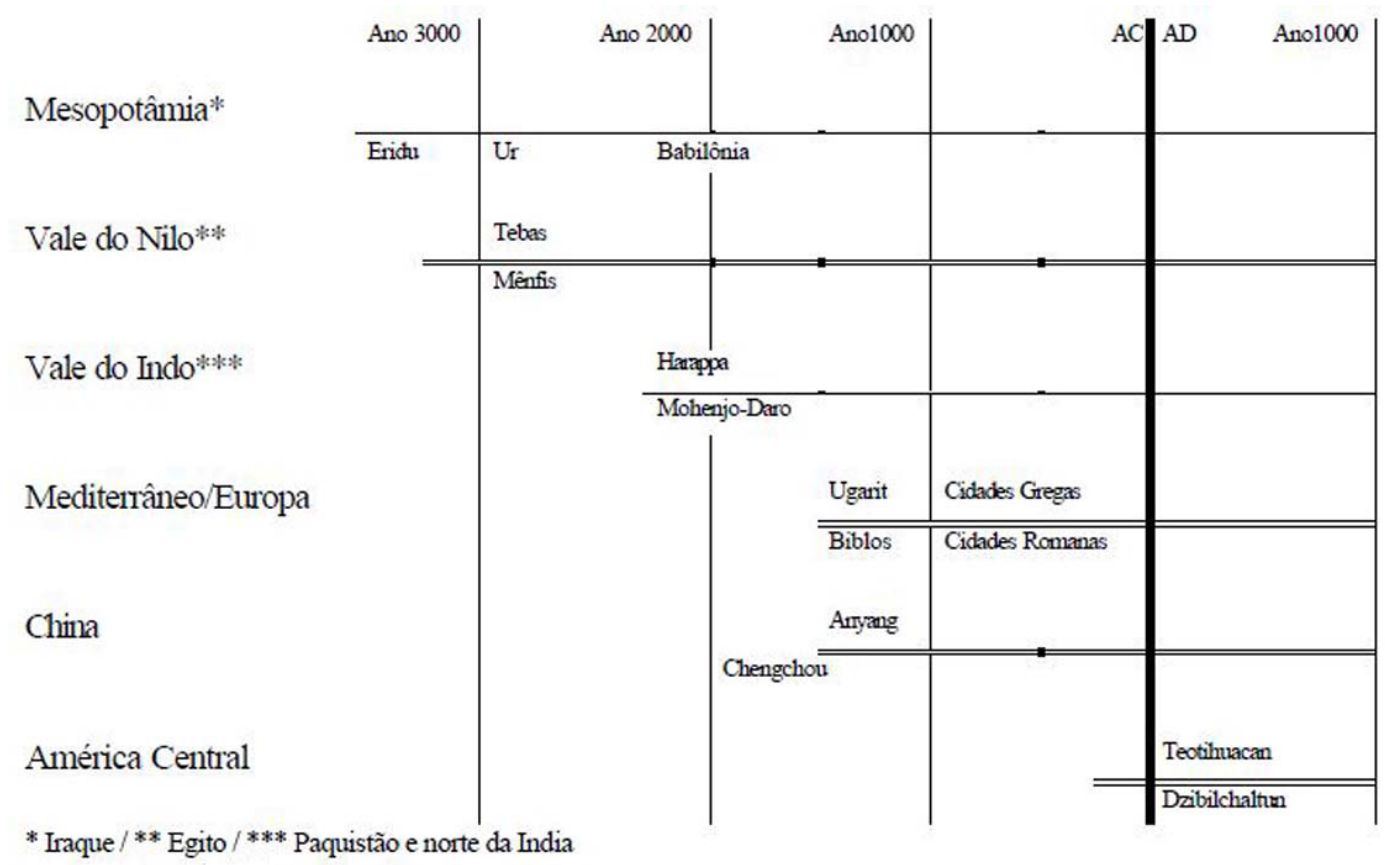

Fuente: Sjoberg (1977).

Sjoberg (1977 apud BRAGA; CARVALHO, 2004), según la Tabla 1, presenta el inicio del surgimiento de las primeras civilizaciones, en la línea del tiempo en cuestión, se observa que las primeras comunidades neolíticas se desarrollaron a lo largo de los ríos, sustancia fundamental para el desarrollo humano. Estas se estaban convirtiendo en grandes centros urbanos como: Mesopotamia = Irán Irak, Valle del Nilo = Egipto, Valle del Indo = Afganistán, Pakistán e India, Mediterráneo/Europa = Grecia y Roma, China y América Central. Para su supervivencia y desarrollo, tuvieron que cuidar un espacio, que con los años se convirtió en territorios, delegados de poderes en todos los niveles de las relaciones sociales. Raffestin y Santana (2013, p. 50), afirman que "[...] el espacio es anterior al territorio. El territorio se forma a partir del espacio, es el resultado de una acción llevada a cabo por un actor sintagmático, (actor que realiza un programa) a cualquier nivel". En su discurso, continúa especificando que el hombre territorializa el espacio. Así, comprobaremos que los espacios se identifican según el panorama de la época, territorializado o no. En la Edad Media, la tríada: espacio, territorio y territorialidad se establecía mayoritariamente con fronteras demarcadas y grandes murallas que dividían los feudos, que 
estaban unidos por caminos con función económica. Su parte exterior estaba protegida por un foso. Guedes (2008, p. 40) señala que: "En la época medieval, el foso era una parte activa de los sistemas de defensa". El mismo era utilizado para contener invasiones y también, como puente del castillo feudal hacia el mundo. En latín el foso es parte de una arquitectura militar medieval Otras formas de abrir vías de comunicación en aquella época fueron las Cruzadas, expediciones con el objetivo de difundir el catolicismo. Pedrero-Sánchez (2000, p. 25), señala que el inicio de la Edad Media fue la "[...] descomposición del Imperio Romano, la implantación del cristianismo y la migración de los pueblos germánicos". Este mismo autor señala que es solo uno de los que estudian el periodo medieval, que se define como una transición entre la antigüedad y la modernidad. Sin embargo, sabemos que también es una parte constitutiva del avance de la integración de la comunicación de las vías que tenemos hoy en día, para definir las fronteras geográficas, dar cabida a los pueblos inmigrantes y atravesar las vías religiosas. El cuadro 2 muestra los principales hitos históricos que conectaron las carreteras y acercaron a las civilizaciones. El cuadro 2 muestra los principales hitos históricos que han conectado caminos y acercado civilizaciones.

Cuadro 2 - Hitos históricos: colonialismo e imperialismo

\begin{tabular}{|c|c|}
\hline Colonialismo & Imperialismo \\
\hline Fecha: siglo XVI y XVIII & Fecha: siglo XIX y parte del XX \\
\hline $\begin{array}{l}\text { La búsqueda de tierras por parte de los } \\
\text { europeos. Con las grandes navegaciones. }\end{array}$ & $\begin{array}{c}\text { Conquistas por la riqueza mineral: principales territorios } \\
\text { en África y Asia. }\end{array}$ \\
\hline $\begin{array}{c}\text { Disputa por: parte de España, Portugal, } \\
\text { Francia, Holanda e Inglaterra a los territorios } \\
\text { americanos. }\end{array}$ & $\begin{array}{l}\text { Dominación de los territorios africanos y asiáticos por } \\
\text { parte de las grandes potencias de la época: Inglaterra, } \\
\text { Estados Unidos, Francia, Holanda, Portugal y etc. }\end{array}$ \\
\hline $\begin{array}{l}\text { La fiebre del oro y el intercambio de } \\
\text { especias. }\end{array}$ & Búsqueda de materias primas y mano de obra \\
\hline
\end{tabular}

Fuente: Elaboración de los autores (2021).

La señalización de la Edad Moderna llegó con el movimiento comercial en torno a los castillos medievales, por parte de los burgueses, (una clase social de comerciantes en ascenso), estos lugares también pasaron a ser conocidos como burgos. Estos movimientos se extendieron al extranjero. Podemos con una breve reflexión, etiquetar este periodo como el precursor del capitalismo en el mundo, con características firmes, como: carrera comercial y dominación. En cuanto a la colonización brasileña, ésta entró en el territorio por medio de ciclos económicos. Por lo tanto, el escenario mencionado duró hasta el siglo XIX, verificando-se por la escala mundial. A partir de ese momento, aparece un nuevo aspecto debido al crecimiento de las industrias que requieren materias primas y mano de obra; estos espacios se agudizan en los continentes africano y asiático.

Canclini (2003, p. 23), respecto a las diferencias en este contexto, como una forma de inconveniente, señala que, "Las once lenguas que se hablan en el Parlamento Europeo corresponden a diferencias culturales que no se disuelven con los acuerdos económicos de integración". Lo diferente, lo nuevo se ve superado por la necesidad de crecimiento e integración capitalistas.

\subsection{Apertura de caminos}

Con la aceleración económica mundial, llegó la globalización, por lo que cada vez más 
se necesitaba construcciones que permitieran la comunicación y disposición de bienes, ya sea por tierra, aire o mar, para que las importaciones y exportaciones también pudieran tener la movilidad necesaria.

Sin embargo, históricamente esta función, pasó por varios caminos hasta llegar al escenario al que se encuentra presente actualmente. En relación a la Ruta Bioceánica: Brasil, Paraguay, Argentina y Chile, esta idealización se establece porque hay un factor que precede al período en el que vivimos, provocando las necesidades de las rutas de transición. En este contexto, es importante realizar puntuaciones que faciliten la comprensión del título propuesto, tales como: los canales de riego y transiciones; las transacciones comerciales alrededor de los castillos medievales (llamados burgos) con sus extensiones y finalmente, las entradas y banderas en territorio brasileño, hito histórico de transición en el argumento de la Ruta Bioceánica: Brasil, Paraguay, Argentina y Chile.

\subsection{Canales interactivos de irrigaciones y transiciones}

Este sub-elemento hace analogía con los canales de los ríos y su funcionalidad. Sabemos que canal es un medio de distribución o transmisión de mercancías. Desde la Ruta Bioceánica en Brasil, Paraguay, Argentina y Chile también tiene esta función, fortaleciendo las relaciones oceánicas (Atlántico y Pacífico), así como los primeros canales de riego ya sea en otros océanos o carreteras. Según Costa y Souza (2006, p. 1), "La civilización de la antigua Mesopotamia prosperó entre los valles de los ríos Tigres y Éufrates hace más de 6000 años, utilizando, aunque de manera rudimentaria, el método de riego superficial". Los canales de riego en el antiguo Egipto, en opinión de George (2018), también condujeron al desarrollo local de esta antigua civilización, y fueron ejemplos y fundamentos significativos para la economía mundial. Hoy contamos con numerosos canales económicos y turísticos facilitadores que acortan la distancia y el tiempo de comunicación. Coelho (2011), presenta los principales canales de navegación del mundo (Cuadro 3).

Cuadro 3 - Los principales canales de navegación del mundo

\begin{tabular}{|c|l|}
\hline De Panamá & $\begin{array}{l}{[\ldots] \text { conecta el Océano Atlántico con el Océano Pacífico, localizado en }} \\
\text { Panamá. }\end{array}$ \\
\hline De Suez & $\begin{array}{l}{[\ldots] \text { conecta el Mar Mediterráneo con el Mar Rojo, y se localiza en }} \\
\text { Egipto. }\end{array}$ \\
\hline De La Mancha & $\begin{array}{l}{[\ldots] \text { une el Mar del Norte con el Océano Atlántico. Ubicado en }} \\
\text { Inglaterra. }\end{array}$ \\
\hline Kiel & $\begin{array}{l}\text { Situado en Alemania, acorta el paso entre el Mar del Norte y el Mar } \\
\text { Báltico [... }]\end{array}$ \\
\hline Houston Ship & $\begin{array}{l}\text { Ubicado en los Estados Unidos, conecta Houston, Texas con el Golfo } \\
\text { de México. }\end{array}$ \\
\hline Welland & $\begin{array}{l}\text { Situado en Canadá, [...] conecta el lago Erie con el lago Ontario, y es } \\
\text { parte de Saint Lawrence Seaway. } \\
{[\ldots] \text { conecta el Océano Atlántico con los grandes Lagos de América del }} \\
\text { Norte. }\end{array}$ \\
\hline
\end{tabular}




\begin{tabular}{|c|l|}
\hline \multirow{2}{*}{ Meno-Danubio } & $\begin{array}{l}\text { [...] es un canal alemán de } 171 \text { kilómetros que hace la conexión } \\
\text { entre el río Danubio y el río Meno, conectando ambos con el río } \\
\text { Reno, permitiendo asíla ruta de transporte fluvial más corta desde } \\
\text { Constanza (Rumanía, Mar Negro) hasta el puerto de Rotterdam } \\
\text { (Países Bajos, Mar del Norte). }\end{array}$ \\
\hline De Corinto & $\begin{array}{l}\text { [...] es un canal excavado en la roca del Istmo de Corinto a finales del } \\
\text { siglo XIX. [...] impide el paso de cargueros internacionales. }\end{array}$ \\
\hline De Midi & $\begin{array}{l}\text { [... es un canal artificial situado en la región de Midi de Francia. Es el } \\
\text { canal marítimo más antiguo de Europa aún en funcionamiento. [...] } \\
\text { Navegable entre el río Garona, a la altura de Tolosa, y Sète, en el mar } \\
\text { Mediterráneo [...] a lo largo de su recorrido se encuentran trescientas } \\
\text { cincuenta obras de arte, entre puentes, esclusas y acueductos. [...] } \\
\text { Coelho (2011) }\end{array}$ \\
\hline
\end{tabular}

Fuente: Coelho (2011).

Un canal, ya sea natural o artificial, establece comunicación por navegación o riego, para que este último traiga agua al espacio proyectado (caso del Antiguo Egipto y Mesopotamia). Un canal natural es utilizado por la explotación geográfica, y en ambos pasajes de bienes para los consumidores tiene como objetivo ser rápido.

Algunos canales destacan por sus cualidades turísticas, como se señala en la Tabla 3, al referirse al Canal Midi. Coutinho (2017), expone que, este canal es conocido por su vocación turística, con carriles de bicicletas, y su inicio en Agde, las orillas del Mediterráneo conducen a Carcassone, un camino considerado preferentemente por los turistas, no solo por el paisaje, sino también por la venta de alimentos y otros productos locales.

Vemos que este engranaje milenario ha desarrollado las estructuras económicas, sociales y culturales en las cuatro partes del mundo. En la misma medida en que se desencadenan estos impulsos, porque sumariamente imposibles, estas tres estructuras operan de forma aislada. El sector económico combinado con la viabilidad comercial es la razón que justifica la apertura de caminos, acoplado sucesivamente a esto viene la explotación cultural regional que desencadena el turismo.

\subsection{Rutas comerciales desde el período Medievo hasta la contemporaneidad}

La ruta es un camino ya sea para el transporte de objetos o el movimiento de personas, y puede ser por tierra o por agua. El Corredor Bioceánico y el Ferrocarril Bioceánico es un proyecto de la ruta más reciente del Cono Sur de América, que debe conectar los océanos: Atlántico y Pacífico. Tal recurso es bastante antiguo en el mundo, ejemplificamos en este sentido el comercio local medieval que a partir de este desarrollaron las rutas comerciales internacionales. Lacerda y Neder (2007, p. 2), señalan la ruta comercial del norte y la ruta comercial del sur, realizada principalmente a través del mar Mediterráneo, teniendo como puertos más importantes los de Barcelona, Marsella, Génova, Venecia, Túnez, Trípoli y Constantinopla.

El período de transición de la Edad Moderna y la época medieval a la contemporánea, tuvo grandes expediciones a las que planificaron y siguieron sus rutas de conquista y exploración territorial. Entre los más expresivos de estos almacenes comerciales se encuentran las ciudades italianas de Génova y Venecia. Con los turcos otomanos tomando Constantinopla en 1453, los comerciantes necesitaban buscar otro camino para llevarlos directamente a las Indias. Los

INTERAÇÕES, Campo Grande, MS, v. 22, n. 4, p. 1353-1365, out./dez. 2021. 
portugueses deseaban llegar a las Indias, emigraron a África y tomaron posesión de las nuevas tierras y comenzaron su colonización de explotación en el territorio brasileño.

Las rutas, caminos y carreteras, efectuados en el territorio brasileño, siguieron la historia económica, no sólo nacional, sino también la de otros países que tenían una conexión de favoritismo económico. Por lo tanto, durante Brasil colonia e Imperio Inglaterra, estaba fuertemente relacionada, principalmente en asuntos relacionados con el comercio de esclavos y la circulación aurífero. Mientras tanto, los ciclos económicos en Brasil, como pau-brasil, caña de azúcar, oro, algodón, café y el caucho, según Machado (2019), pueden marcarse como períodos históricos brasileños. Otro factor digno de mención son las entradas y banderas, hechas por los bandeirantes de São Paulo. Taunay (1951, p. 21), afirma que: "La idea de que las tierras al oeste pertenecían a Castilla, la repudiaron los paulistas desde el siglo XVI, un pretexto probable para la legitimación de sus incursiones por el interior español a la búsqueda de indios".

\subsection{Las entradas y banderas - marco histórico de transición económico brasileño}

Las entradas y banderas, de penetración colonialista, también pueden reflejarse como uno de los hitos territoriales brasileños de expansiones espaciales e interconexiones. En la misma medida, no solo de explotación, sino también de estrechamiento comercial, con un salto de temporalidad, que se convirtió en una etapa de transacciones económicas en las regiones del Sureste y Centro Oeste. La penetración en el interior de Brasil se produjo principalmente a través de entradas y banderas. Las primeras fueron expediciones oficiales (organizadas por el gobierno) que salieron de la costa hacia el interior de Brasil y contó con el apoyo financiero de la Metrópoli. Las primeras entradas, que ocurrieron en el norte y noreste del país, apuntaron a la exploración territorial, mapear ríos, montañas, establecer corrales para la ganadería y rozados para la agricultura auxiliar y también reconocieron las drogas del interior del país; capturaron esclavos negros fugitivos, entre otros y fueron compuestos en su mayoría, por soldados portugueses y brasileños (al servicio de las provincias). Esta información fue enviada a Portugal, con el objetivo de aumentar el conocimiento y permitir la colonización del interior de Brasil (FAUSTO, 2013).

Las banderas eran expediciones organizadas y financiadas por particulares, principalmente paulistas; salieron de São Paulo y São Vicente, principalmente hacia las regiones del Centro Oeste y sur de Brasil. Su principal objetivo era descubrir minas de oro, plata y piedras preciosas y fueron dirigidas por paulistas Ilamados de bandeirante, y tenían en su composición familia, agregados, blancos pobres y mamelucos, las banderas atacaban misiones jesuíticas, capturando indios, que serían comercializados como esclavos (FAUSTO, 2013).

Ambos aluden al sector económico, que actualmente está muy extendido en otros, como la cultura y el turismo. Brasil, partiendo desde São Paulo hacia el interior de Brasil, retratando la ruta de RILA, siguiendo prácticamente el camino inicial.

Durante los siglos XVII y XVIII, las incursiones en las que los portugueses colonialistas permeaban en obediencia al Tratado de Tordesilhas, (línea imaginaria que separaban las tierras del dominio español del portugués) el Sertanismo Contrato. En la contribución de Ramos (2008), la actividad consistía en capturar negros forajidos y luchar contra tribus indígenas rebeldes y quilombolas. Las rutas de la minería de las monzones, salen de São Paulo y se dirigen hacia Cuiabá, Goiás y Vila Rica. Ya que siempre ha sido notorio para el país que en estas regiones se encontraban los mayores yacimientos de oro. Luego, se encuentran en el mismo el trayecto de

INTERAÇÕES, Campo Grande, MS, v. 22, n. 4, p. 1353-1365, out./dez. 2021. 
las embestidas de caza al indio, mercancía de exportación, después de pau-brasil (RIBEIRO, 2015). Esta mano de obra, era de fundamental importancia, pues los indios eran los verdaderos dueños del territorio y conocían los bosques, ríos y caminos a explorar como ningún otro ser viviente de la época. La Ruta Bioceánica conecta el Océano Atlántico desde la costa Paulista, cortando el estado de São Paulo, penetrando en el Estado de Mato Grosso do Sul (MS), puntuada: la ciudad de Campo Grande/MS, Porto Murtinho/MS, Carmelo-Peralta/Paraguay, Argentina y Chile. A través de ferrocarriles y carreteras, este camino sigue impulsando, y por qué no, afirmar la marcha hacia el Oeste en una segunda etapa. En este sentido pasa por la línea fronteriza brasileña hasta este corredor logístico incluyendo a los países del Mercado Común del Sur (Mercosur). Los movimientos comerciales de los puertos brasileños, especialmente Santos, São Paulo (SP), justifica la necesidad de RILA, facilitando el tránsito de entrada y salida de servicios, no sólo de mercancías sino también de personas (FALCÃO; CORREIA, 2012).

\section{METOdOLOGÍA}

Para realizar el estudio reflexivo y comprender la necesidad de esta unión territorial, se utilizó el método deductivo con cobertura sistémica, a través de búsqueda en libros, periódicos, sitios web, documentos primarios, señalando los trabajos que daban soporte al trabajo en pantalla. Para una mejor comprensión del lector, se decidió presentar mapas y tablas ilustrativas sobre el contenido mostrado.

\section{RESULTADOS DE LAS INTERACIONES DEL PODER CULTURAL}

Las vías de endurecimiento económico de hoy permean los sectores cultural y turístico. Coutinho (2017) aduce el Canal de Midi, en Francia, como un punto de turismo de aventura, que fue construido artificialmente para conectar el Mar Mediterráneo con el Atlántico, facilitando el tránsito de embarcaciones comerciales. Con un artículo similar Scirea (2020), presenta el Canal de La Mancha (conexión entre Inglaterra y Francia), como una de las rutas ciclistas más famosas del continente europeo. En el camino hay pueblos, hermosos paisajes con posadas y restaurantes. Por lo tanto, el camino o ruta de RILA debe exaltar los atractivos locales, sus características naturales y el patrimonio histórico local.

Quadro 4 - Sugestión de puntos culturales RILA

\begin{tabular}{|c|c|c|}
\hline Países & Ciudades & Objeto Cultural \\
\hline Brasil & $\begin{array}{c}\text { Campo Grande - Porto Murtinho, } \\
\text { MS }\end{array}$ & $\begin{array}{l}\text { - Feria Central - Campo Grande (CG); } \\
\text { - Travesía: río Paraguay contemplación a la puesta de } \\
\text { sol - Prefeitura Municipal de Porto Murtinho }\end{array}$ \\
\hline Paraguay & $\begin{array}{l}\text { Carmelo Peralta - Mariscal José } \\
\text { Félix Estigarribia - Boquerón - } \\
\text { Pozo Hondo }\end{array}$ & - Exploración gastronómica, polka paraguaya y danza. \\
\hline Argentina & $\begin{array}{c}\text { Misión La Paz - Tartagal - Jujuy - } \\
\text { Salta }\end{array}$ & $\begin{array}{l}\text { - En Jujuy Cerro con } 33 \text { tonalidades; } \\
\text { - Ios siete colores de las montañas; } \\
\text { - Salinas del norte argentino; } \\
\text { - En Salta: se puede contemplar la ruptura de las } \\
\text { conchas. }\end{array}$ \\
\hline
\end{tabular}

INTERAÇÕES, Campo Grande, MS, v. 22, n. 4, p. 1353-1365, out./dez. 2021. 


\begin{tabular}{|c|c|c|}
\hline Países & Ciudades & Objeto Cultural \\
\hline Chile & $\begin{array}{l}\text { Puertos de las ciudades de } \\
\text { Mejillones - Iquique }\end{array}$ & $\begin{array}{l}\text { - En Mejillones hay sitios de mamíferos como nutrias } \\
\text { marinas, leones marinos comunes y del sur, así como } \\
\text { es posible observar diversas especies de delfines. La } \\
\text { ciudad también ofrece pesca deportiva y de alto mar. } \\
\text { lquique, según Senatur es una ciudad con extensas } \\
\text { playas. Su zona franca hace que reciba miles de } \\
\text { visitantes al año. Además del comercio, la ciudad } \\
\text { también ofrece una cocina variada, una mezcla de } \\
\text { sabores de países vecinos. }\end{array}$ \\
\hline
\end{tabular}

Fuente: Ferreira, Castilho y Oliveira (2019).

Desde Campo Grande/MS hasta los puertos en las ciudades de Mejillones, Iquique en Chile, la visión turística cultural de los países RILA/Mercosur es similar por proximidad territorial. En este caso nos estamos refiriendo básicamente no a temas ambientales, como el caso ya mencionado aquí, como la puesta de sol en Porto Murtinho/MS, sino gastronómicamente podemos mencionar la chipa, el tereré, la sopa paraguaya y otros. Desde la música y la danza, como la polca paraguaya y así la mezcla cultural se extiende en sus alrededores en extensiones territoriales vecinas. Se identifica por ejemplo en Logrado de Argentina, el dulce de leche, el alfajor y otros, así como el aprecio por el tango. Barretto (2016), afirma que el turismo es una materia prima elaborada (recursos naturales) o cultura material y simbólica (recursos culturales). Sin embargo, para Barretto (2014), este es un fenómeno diversificado, puede ser emisivo, es decir, enviar turistas para fuera o los receptivos reciben a los que vienen de fuera. En este sentido, es de fundamental importancia trabajar en el conocimiento de la población local para que esta conozca el potencial turístico de su región y sus vecinos, estar preparado para recibir es ser un propagador de su identidad. La diversidad del turismo, ya sea, el tiempo actuando como agente social, emisor o receptor es lo que define el pulso turístico regional. Cuando el individuo en un ambiente exógeno, necesita propagar lo que vive y lo que su lugar tiene para emitir; en una situación endógena, la calidad de la recepción es un parámetro evaluativo para la producción turística continua. Barretto (2003), ya dijo que las relaciones turísticas dependen de las relaciones turista-anfitrión. En cuanto a ser emisor y receptor turístico, el sector cultural comparte esta idea, que, a visión de Santana, Maracajá y Machado (2021, p. 97), "El turismo cultural presenta un potencial de difusión y fortalecimiento de la cultura y de la historia del propio entorno receptor, y constituye una actividad prometedora". No hay dudas sobre el desarrollo local que lleva a cabo el turismo. Diversos estudios e investigaciones destacan que este indicador, Marques (2021) en bibliografía reciente contribuye a esta investigación, estableciendo que, resulta en una gran cantidad de beneficios para las comunidades locales como factor de desarrollo. Como propuesta de planificación del turismo cultural para RILA, aquí está la sugerencia, para la preparación de folletos informativos sobre cultura material e inmaterial; señales con rutas culturales desde Porto Murtinho hasta el Puerto de Mejillones e Iquique/Chile e incentivo a la creación de cafés, restaurantes, hoteles, tours de uso regional entre otras alternativas, como propuestas de desarrollo turístico. Kohler y Durand, (2007, p. 188), citan a McKerchee y Du Cros, que definen "El turismo cultural como el consumo turístico de atracciones previamente clasificadas como culturales". Es decir, las clasificaciones, las puntuaciones culturales de RILA lo hacen necesario para una mayor integración del guión. 


\section{CONSIDERACIONES FINALES}

El derecho a la locomoción humana no está restringido sólo al hombre en el derecho a ir y venir. Podemos afirmar que esto está presente hoy día en el transporte de mercancías, ya que es por su servicio, que con el tiempo se fueron creando vías de comunicación; Junqueira e Peetz (2008) corroboran que en la historia se ha demostrado el dominio humano sobre la naturaleza y su capacidad de transformarla para satisfacer sus necesidades. La aceleración económica, que se está viendo, promueve innovaciones de diversos sectores económicos, así como la que se aborda en estas áreas culturales y turísticas.

El marco del tema - RILA, su influencia cultural y los desafíos turísticos, estuvieron presentes en esta investigación para lograr que este gran emprendimiento, tenga el poder de sostener el desarrollo local.

\section{REFERENCIAS}

BARRETTO, Margarita. Manual de iniciação ao estudo do turismo. São Paulo: Papirus, 2016.

BARRETTO, Margarita. O imprescindível aporte das ciências sociais para o planejamento e a compreensão do turismo. Revista Horizontes antropológicos, Porto Alegre, v. 9, n. 20, p. 15-29, 2003.

BRAGA, Roberto; CARVALHO, Pompeu Figueiredo. Cidade: espaço da cidadania. In: GIOMETTI, A.; BRAGA, R. (Org.). Pedagogia cidadã: cadernos de formação. Ensino de Geografia. São Paulo: UNESP-PROPP, 2004. p. 105-120.

CANCLINI, Néstor García. A globalização imaginada. São Paulo: Iluminuras, 2003.

COELHO, Ludmar Rodrigues. Os principais canais de navegação do mundo. Logística Descomplicada, [s.l.], 2011. Disponible en: http://www.logisticadescomplicada.com. Acceso el: 27 mayo 2021.

COSTA, Raimundo Nonato Távora; SOUZA, Danielle Ferreira. Gestão sustentável no Baixo Jaguaribe. Fortaleza: Embrapa Agroindústria Tropical, 2006.

COUTINHO, Douglas. Cicloviagem na trilha do "Canal du Midi", na França. Trilhas e aventuras, São Paulo, 2017. Disponible en: https://www.trilhaseaventuras.com.br. Acceso el: 7 jun. 2021

FALCÃO, Viviane Adriano; CORREIA, Anderson Ribeiro. Eficiência portuária: análise das principais metodologias para o caso dos portos brasileiros. Journal of Transport Literature, São José dos Campos, v. 6, n. 4, p. 133-46, 2012.

FAUSTO, Boris. História do Brasil. São Paulo: USP, 2013.

FERNANDES, Euclécio Alves. A evolução da comunicação impactada pela tecnologia. Ideias e InovaçãoLato Sensu, Aracaju, v. 3, n. 2, p. 93-102, 2016.

FERREIRA, Magali Lúzio; CASTILHO, Maria Augusta; OLIVEIRA, Edilene Maria. Brasil, Paraguai, Argentina e Chile/Rota Bioceânica: relações culturais no território vivido. Interações, Campo Grande, v. 20, n. especial, p. 69-89, 2019.

GEORGE, Andrew. The epic of Gilgamesh. Amsterdam: Amsterdam University Press, 2018.

GUEDES, César. Identificação do Fosso da Cerca de Torre de Moncorvo. In: CONGRESSO DE ARQUEOLOGIA

INTERAÇÕES, Campo Grande, MS, v. 22, n. 4, p. 1353-1365, out./dez. 2021. 
DE TRÁS-OS-MONTES, ALTO DOURO E BEIRA INTERIOR, 3., 2008, Vila Nova de Foz Côa. Anais [...]. Vila Nova de Foz Côa: Associação Cultural Desportiva e Recreativa de Freixo de Numão, 2008. p. 39-44.

JUNQUEIRA, Antonio Hélio; PEETZ, Márcia da Silva. Mercado interno para os produtos da floricultura brasileira: características, tendências e importância sócio-econômica recente. Ornamental Horticulture, v. 14, n. 1, p. 37-52, 2008.

KÖHLER, André Fontan; DURAND, José Carlos Garcia. Turismo cultural: conceituação, fontes de crescimento e tendências. Turismo-Visão e Ação, Balneário Camboriú, v. 9, n. 2, p. 185-98, 2007.

LACERDA, Sueli Pereira; NEDER, Marco Antonio Villarta. O Surgimento do comércio medieval. In: ENCONTRO LATINO AMERICANO DE INICIAÇÃO CIENTÍFICA, 11.; ENCONTRO LATINO AMERICANO DE PÓS-GRADUAÇÃO, 7., 2007, São José dos Campos. Anais [...]. São José dos Campos: Universidade do Vale do Paraíba, 2007.

MACHADO, Jefferson Evandro. Ciclos econômicos brasileiros. História do Brasil, [s.l.], 2019. Disponible en: https://www.historiadobrasil.net/resumos/ciclos_economicos.htm. Acceso el: 8 jun. 2021.

MARQUES, Raquel Sousa. O turismo cultural e a problemática da capacidade de carga do património: estudo da dimensão social do caso da Catedral do Porto. Ge-conservacion, Madrid, v. 19, n. 1, p. 320-28, 2021.

NAQUET-VIDAL, Pierre; BERTIN, Jacques. Atlas histórico: da pré-história aos nossos dias. Lisboa: Círculo de Leitores, 1987.

PEDRERO-SÁNCHEZ, Maria Guadalupe. História da Idade Média. São Paulo: UNESP, 2000.

PERLES, João Batista. Comunicação: conceitos, fundamentos e história. [S.I.]: Biblioteca on-line de Ciências da Comunicação, 2007. Disponible en: http://www.bocc.ubi.pt/pag/perles-joao-comunicacao-conceitosfundamentos-historia.pdf. Acceso el: 8 jun. 2021.

PINSKY, Jaime. As primeiras civilizações. São Paulo: Contexto, 2005.

PROUS, André. O Brasil antes dos brasileiros: a pré-história do nosso país. São Paulo: Zahar, 2006.

RAFFESTIN, Claude; SANTANA, Octavio Martín González. Por una geografía del poder. Michoacán: El colegio de Michoacán, 2013.

RAMOS, Jefferson Evandro Machado. O sertanismo de contrato foi uma atividade realizada por bandeirantes brasileiros. História do Brasil, [s.l.], 2008. Disponible en: https://www.historiadobrasil.net/brasil_colonial/ sertanismo_contrato.htm. Acceso el: 8 jun. 2021.

RIBEIRO, Darcy. O povo brasileiro: a formação e o sentido do Brasil. São Paulo: Global Editora e Distribuidora Ltda, 2015.

SANTANA, Juliana Cardoso; MARACAJÁ, Kettrin Farias Bem; MACHADO, Petruska By Araújo. Turismo cultural y sostenibilidad turística: mapeo del desempeño científico desde Web of Science. Turismo y Sociedad, Bogotá, v. 28, p. 95-113, 2021.

SCIREA, Bruna. Cicloturismo: os 8 dos mais belos e famosos roteiros de bicicleta do mundo. Melhores Destinos, [s.l.], 2020. Disponible en: https://www.melhoresdestinos.com.br. Acceso el: 8 June 2021.

SJOBERG, Gideon. Origem e evolução das cidades. In: DAVIS, Kingsley et al. Cidades: a urbanização da humanidade. Rio de Janeiro: Zahar, 1977. 
TAUNAY, Afonso d'Escragnolle. História das bandeiras paulistas. São Paulo: Edições Melhoramentos, 1951.

YOKOYAMA, Henrique Hiroto; BORGES, Robertson de Carvalho; SILVA, Luiz Gabriel, RIBEIRO, Ana Clara Arruda Dias. Construindo um ábaco reciclável pára novos saberes e utilização para reforçar as 4 operações básicas. South American Journal of Basic Education, Technical and Technological, v. 5, n. 2 (supl. 1), p. 1-297, 2018. [Anais da IV Mostra Acreana de Educação, Ciência, Tecnologia e Inovação- Viver Ciência, 29 a 31 ago. 2018, Rio Branco, AC].

\section{Sobre las autoras y el autor:}

Magali Luzio Ferreira: Doctorado y Máster en Desarrollo Local por la Universidad Católica Dom Bosco (UCDB). Grado en Historia por las Faculdades Unidas Católicas de Mato Grosso (FUCMT). Jefe de la División de Educación y Diversidad de la Superintendencia de Gestión de Políticas Educativas de la Secretaría Municipal de Educación (SEMED) en Campo Grande, Mato Grosso do Sul. E-mail: luzio.magali@gmail.com, Orcid: https://orcid.org/0000-0002-3420-7582

Maria Augusta de Castilho: Postdoctorado en Lingüística por la Universidad de São Paulo (USP). Doctorado en Ciencias Sociales por la USP. Actualmente, es profesora del curso de Historia y del Programa de Posgrado en Desarrollo Local - Máster/Doctorado de la Universidad Católica Dom Bosco (UCDB), siendo también responsable del Laboratorio de Historia. E-mail: maugusta@ucdb.br, Orcid: http://orcid.org/0000-0001-5235-3164

Waldir Leonel: Doctorado en Medio Ambiente y Desarrollo Regional por la Universidad Anhanguera-Uniderp. Máster en Desarrollo Local por la Universidad Católica Dom Bosco (UCDB). Grado en Turismo por la Universidad Estácio de Sá; y en Ciencias Biológicas por la Universidad Estatal Paulista Júlio de Mesquita Filho (UNESP). Profesor en la Universidad Estatal de Mato Grosso do Sul (UEMS). Superintendente de Gestión de Políticas Educativas de la Secretaría de Educación Municipal (SEMED), en Campo Grande, Mato Grosso do Sul. E-mail: waldir.leonel@gmail.com, Orcid: http://orcid.org/0000-0002-5376-0041 
